\title{
Finite element analysis and fracture resistance testing of a new intraradicular post
}

\author{
Eron Toshio Colauto YAMAMOTO ${ }^{1}$, Clovis PAGANI ${ }^{2}$, Eduardo Galera da SILVA ${ }^{3}$, Pedro Yoshito NORITOMI ${ }^{4}$, André \\ Yugou UEHARA 5 , Daniel Takanori KEMMOKU6
}

\author{
1- DDS, MS, PhD, Department of Restorative Dentistry, São José dos Campos Dental School, Univ. Estadual Paulista - UNESP, São José dos Campos, SP, Brazil. \\ 2- DDS, MS, PhD, Professor, Department of Restorative Dentistry, São José dos Campos Dental School, Univ. Estadual Paulista - UNESP, São José dos \\ Campos, SP, Brazil. \\ 3- DDS, MS, PhD, Professor, Department of Social Dentistry, São José dos Campos Dental School, Univ. Estadual Paulista - UNESP, São José dos Campos, \\ $\mathrm{SP}$, Brazil. \\ 4- PhD, Mechanical Engineer, State University of Campinas (UNICAMP), Campinas, SP, Brazil. \\ 5- Master's student in Mechanical Engineering, State University of Campinas (UNICAMP), Campinas, SP, Brazil. \\ 6- Graduate student in Mechanical Engineering, State University of Campinas (UNICAMP), Campinas, SP, Brazil.
}

Corresponding adress: Eron Toshio Colauto Yamamoto - R. Pedro de Toledo, 19 - Guararema - SP - $08900-000$ - Brasil - Phone: 551146952649 - e-mail: eron.y@terra.com.br

Received: October 6, 2010 - Modification: October 8, 2011 - Accepted: November 6, 2011

\section{ABSTRACT}

\begin{abstract}
$\mathrm{O}$ bjectives: The objective of the present study was to evaluate a prefabricated intraradicular threaded pure titanium post, designed and developed at the São José dos Campos School of Dentistry - UNESP, Brazil. This new post was designed to minimize stresses observed with prefabricated post systems and to improve cost-benefits. Material and methods: Fracture resistance testing of the post/core/root complex, fracture analysis by microscopy and stress analysis by the finite element method were used for post evaluation. The following four prefabricated metal post systems were analyzed: group 1, experimental post; group 2, modification of the experimental post; group 3, Flexi Post, and group 4, Para Post. For the analysis of fracture resistance, 40 bovine teeth were randomly assigned to the four groups $(n=10)$ and used for the fabrication of test specimens simulating the situation in the mouth. The test specimens were subjected to compressive strength testing until fracture in an EMIC universal testing machine. After fracture of the test specimens, their roots were sectioned and analyzed by microscopy. For the finite element method, specimens of the fracture resistance test were simulated by computer modeling to determine the stress distribution pattern in the post systems studied. Results: The fracture test presented

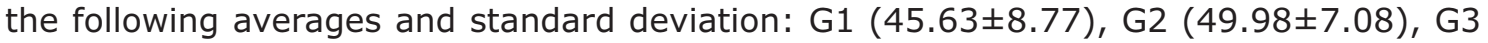

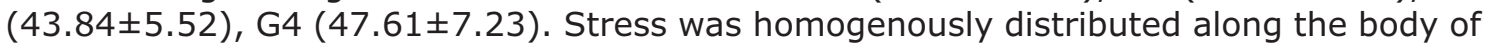
the intraradicular post in group 1 , whereas high stress concentrations in certain regions were observed in the other groups. These stress concentrations in the body of the post induced the same stress concentration in root dentin. Conclusions: The experimental post (original and modified versions) presented similar fracture resistance and better results in the stress analysis when compared with the commercial post systems tested (08/2008$\mathrm{PA} / \mathrm{CEP})$.
\end{abstract}

Key words: Post and core technique. Finite element analysis. Stress fractures.

\section{INTRODUCTION}

Current trends in Dentistry are to reduce clinical steps while maintaining the quality of treatment ${ }^{22}$. In view of this objective, prefabricated post systems have been developed which are easier to install and faster than cast metal cores $^{3}$. The wide variety of commercial brands makes the selection and clinical indication difficult since no single system can be applied to all situations ${ }^{24}$.

Glass fiber posts have shown better results in stress distribution to the roots when compared with metal posts, but the resistance of glass fiber is lower?.

According to Geng, et al. ${ }^{8}$ (2001) and Henry ${ }^{10}$ (1977), photoelastic stress and finite element 
analyses are valuable tools for the study of stress distribution related to intraradicular posts. These methods evaluate mechanical properties and assist in the study of new materials in order to reduce the risk of failures and fractures in the restorative material and tooth structure. Cohen, et al. ${ }^{5}$ (1999) compared the retention and photoelastic stress pattern under vertical and oblique loading of two prefabricated post systems. The posts systems studied were Flexi Post (a threaded metal post) and C-Post (a passive carbon-fiber post). Flexi Post presented a higher retention force $(1180 \mathrm{~N})$ than C-Post $(171 \mathrm{~N})$. Photoelastic analysis indicated minimal stresses for both post systems, but Flexi Post distributed stress more symmetrically than C-Post.

Using the finite element method, Lewgoy, et al. ${ }^{14}$ (2003) compared prefabricated stainless steel or titanium Flexi Post and Flexi Flange systems. A homogenous stress distribution pattern was observed for both stainless steel and titanium posts, but the former caused a higher stress than the latter. The Flexi Flange post distributed the stress better, probably because of the presence of a flange in the coronal portion of the post.

Mitsui, et al. ${ }^{18}$ (2004) studied the fracture resistance of bovine teeth restored with five different intraradicular post systems: cast metal posts, titanium posts, glass-fiber posts, carbonfiber posts, and zirconium posts. The titanium posts presented a higher mean fracture resistance value when compared with glass-fiber and zirconium posts and similar values compared with carbon-fiber posts. Similar results were obtained with the cast metal posts when compared with the prefabricated posts. The authors concluded that titanium and carbon-fiber posts are the most indicated.

In view of the advantages and disadvantages of the use of active metal posts, a prefabricated threaded titanium post was developed and subjected to fracture resistance testing, microscopic analysis of cracks and finite element analysis. The objective of this study was to compare the experimental post with two commercial post systems. This new post was designed to minimize stresses observed with prefabricated post systems and to improve cost-benefits. The hypothesis is that there will be differences in stress distribution and fracture resistance in the different post systems.

\section{MATERIAL AND METHODS}

\section{Prefabricated titanium post}

Based on a review of current literature, a prefabricated metal post (Figure 1) was developed at the São José dos Campos School of Dentistry, UNESP (UNESP-SJC), Brazil. This post was designed to reduce commercial costs and to minimize stresses to the root structure.

The post head was designed in such a way that it would be supported on the coronal remnant in order to better distribute stresses to the root. A squarewrench groove as used in implants was introduced in the post head (Figure 2) for post cementation. Thus, tooth preparation only requires the use of Largo burs and the square wrench is employed for insertion of the post, two easily handled instruments that are normally found in dental offices or easily purchased, thus reducing the cost of the system. A modified design of the post consisted of an increase in neck diameter (Figure 3 ). This small change increases post resistance, reducing possible fracture in this region.

\section{Fracture resistance test}

Forty bovine teeth were used in the fracture resistance test. The teeth were randomly divided according to the type of intraradicular post used: group $1-\varnothing 1.75 \mathrm{~mm}$, post developed at UNESPSJC; group $2-\varnothing 1.75 \mathrm{~mm}$, modified post developed at UNESP-SJC; group 3, Flexi Post No. 2 - ø1.4 mm (EDS, S. Hackensack, NJ, USA ), and group 4, Para Post No. 7 - $\varnothing 1.75$ mm (Coltene Whaledent, Cuyahoga Falls, $\mathrm{OH}$, USA).

For simulation of the periodontal ligament, wax

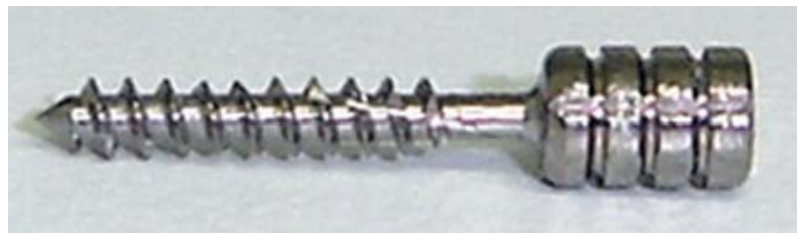

Figure 1- Post developed in this study

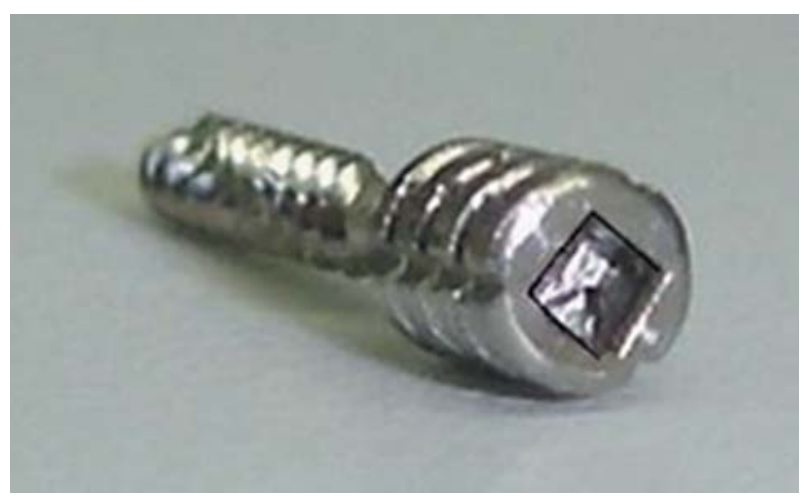

Figure 2- Groove for square wrench

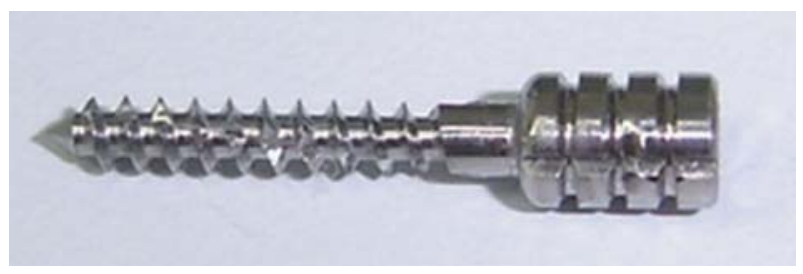

Figure 3- Modified post 
\#7 (Epoxiglass, Diadema, SP, Brazil) was heated in a container with a controlled temperature and the root was immersed to form a $0.3 \mathrm{~mm}^{4}$. This thickness was measured with a caliper before and after application of wax. The root with wax was embedded in polyurethane resin (Axson Technologies, Cergy Cedex, France) to obtain a space of $0.3 \mathrm{~mm}$ around the entire root, which was filled with hydrophilic addition silicone (Elite HD, Zhermak, Badia Polesine, Rovigo, Italy). The teeth were embedded in polyurethane resin, whose characteristics resemble those of human bone ${ }^{6}$.

The posts were cemented with zinc phosphate cement (SS White, Rio de Janeiro, RJ, Brazil). After cementation, the tooth was filled with Z-250 composite resin (3M ESPE, Dental Products, St. Paul, MN, USA) as core material using a cylindrical plastic mold measuring $5 \mathrm{~mm}$ in diameter and 5 $\mathrm{mm}$ in height.

The test specimens (Figure 4) were placed inside a stainless steel device, forming an angle of $45^{\circ}$ between the vertical arm of the universal testing machine (Emic DL 1000, São José dos Pinhais, PR, Brazil) and the long axis of the roots (simulating occlusion of upper and lower anterior teeth of a patient with Angle Class I) and subjected to loading at a crosshead speed of $0.5 \mathrm{~mm} / \mathrm{min}$.

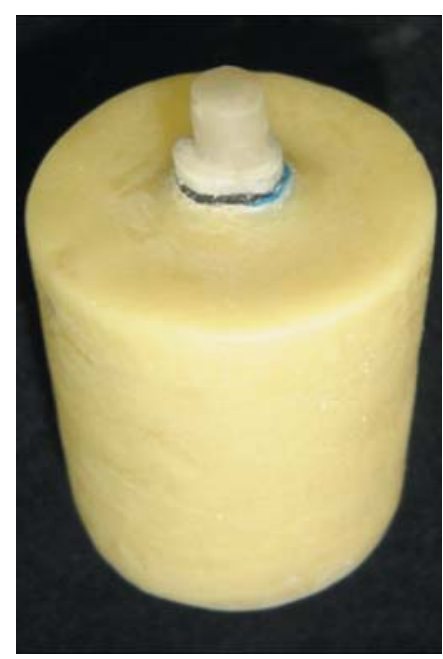

Figure 4- Finished test specimen

\section{Microscopy}

Fractured teeth were embedded in chemically activated acrylic resin using a silicone mold, cut with a cutting device (Labcut 1010, Extec, Enfield, CT, USA) into 1-mm-thick slices, and analyzed under a stereomicroscope to determine the crack trajectory and the failure type.

\section{Finite element method}

Finite element analysis was performed by simulating the experimental study of fracture resistance. The geometry and dimensions of the structures were based on the test specimen of the experimental study. Three-dimensional models were constructed using the Rhinoceros program (McNeel North America, Seattle, WA, USA) and then imported into the Nei Nastran program (Nei Software, Westminster, CA, USA), which was used for finite element analysis.

A controlled mesh defined by solid quadratic tetrahedral elements, which were characterized by pyramids of a triangular base, was used.

The mechanical properties were entered into the Nei Nastran program as an elastic modulus and Poisson coefficient of each simulated material. The models were classified as isotropic (presenting the same properties in any of the directions analyzed), elastic (recovering the original dimensions when the load was removed), and continuous (showing no empty spaces). No consensus exists in the

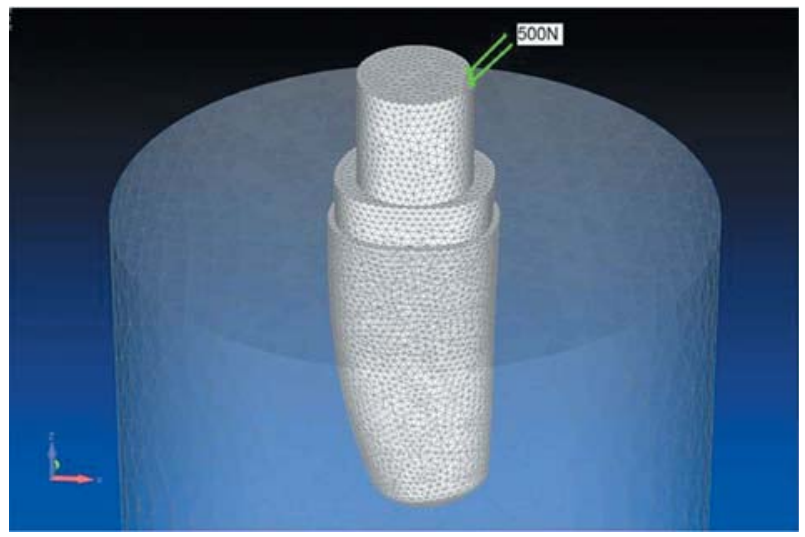

Figure 6- Three-dimensional model

\begin{tabular}{|c|c|c|c|}
\hline Material & Elastic modulus (GPa) & Poisson coefficient & Reference \\
\hline Dentin (bovine) & 13.7 & 0.31 (human dentin) & ${\text { Sano, et al. }{ }^{20}(1994)}^{{ }^{12}(1977)}$ \\
\hline $\begin{array}{c}\text { Silicon (periodontal } \\
\text { ligament) }\end{array}$ & 0.088 & 0.45 (periodontal ligament) & Jamani, et al. $^{19}$ \\
\hline Polyurethane & 0.104 & 0.3 & Completo, et al. $^{6}(2006)$ \\
\hline Composite resin & 21.2 & 0.24 & O'Brien $^{19} 1997$ \\
\hline Titanium & 117 & 0.33 & O'Brien $^{19} 1997$ \\
\hline Stainless steel & 200 & 0.33 & Ho, et al. $^{11}(1994)$ \\
\hline
\end{tabular}

Figure 5- Mechanical properties of the materials and structures 
literature regarding the mechanical properties of the materials and structures. Thus, the most frequently reported values were used. We found no Poisson coefficient for bovine dentin or silicone in a literature review. Since the properties and structure of bovine dentin are similar to those of human dentin ${ }^{21}$, the Poisson coefficient of human dentin was used. The same applies to silicone and the Poisson coefficient of the periodontal ligament was therefore used (Figure 5).

Finite element analysis was performed with the model fixed to the outer region of the cylinder, applying a load of $500 \mathrm{~N}$ to the core at an inclination of $45^{\circ}$ in relation to the long axis of the tooth (Figure 6). A load of $500 \mathrm{~N}$ was applied because this value is close to the mean fracture resistance observed in the experimental study. The contact between structures in the model was considered to be pasted.

\section{RESULTS}

\section{Fracture resistance test}

The mean values and standard deviations of fracture resistance are shown in Table 1. Comparison by one-way analysis of variance $(p<0.05)$ showed no statistically among groups (Table 2 ). Table 3 lists the types of fracture observed in the groups.

With the data from Table 3 the statistical analysis of multiple comparisons for proportions (Table 4) was conducted using Minitab 15 for Windows with macro multprop.MAC. Statistically significant difference $(p<0.05)$ was found only between groups 1 and 3 . The other comparisons were not statistically significant $(p>0.05)$.

\section{Finite element method}

Figures 7 and 8 show the stress distribution in the post and root, respectively. Geometry was found to modify the stress distribution pattern. In group 1 (experimental post) the highest von Mises stresses were concentrated in the cervical region. The stress distribution pattern in root dentin was

Table 1- Means and standard deviation in the fracture resistance test (Kgf)

\begin{tabular}{ccccc}
\hline & Group 1 & Group 2 & Group 3 & Group 4 \\
\hline & Experimental post & Modified post & Flexi Post & Para Post \\
Mean & 45.63 & 49.98 & 43.84 & 47.61 \\
Standard deviation & 8.77 & 7.08 & 5.52 & 7.23 \\
\hline
\end{tabular}

Table 2- One factor analysis of variance

\begin{tabular}{cccccc}
\hline Source & DF & SS & MS & F & P \\
\hline Groups & 3 & 209.3 & 69.8 & 1.33 & 0.28 \\
Error & 36 & 1890.9 & 52.5 & & \\
Total & 39 & 2100.3 & & & \\
\hline
\end{tabular}

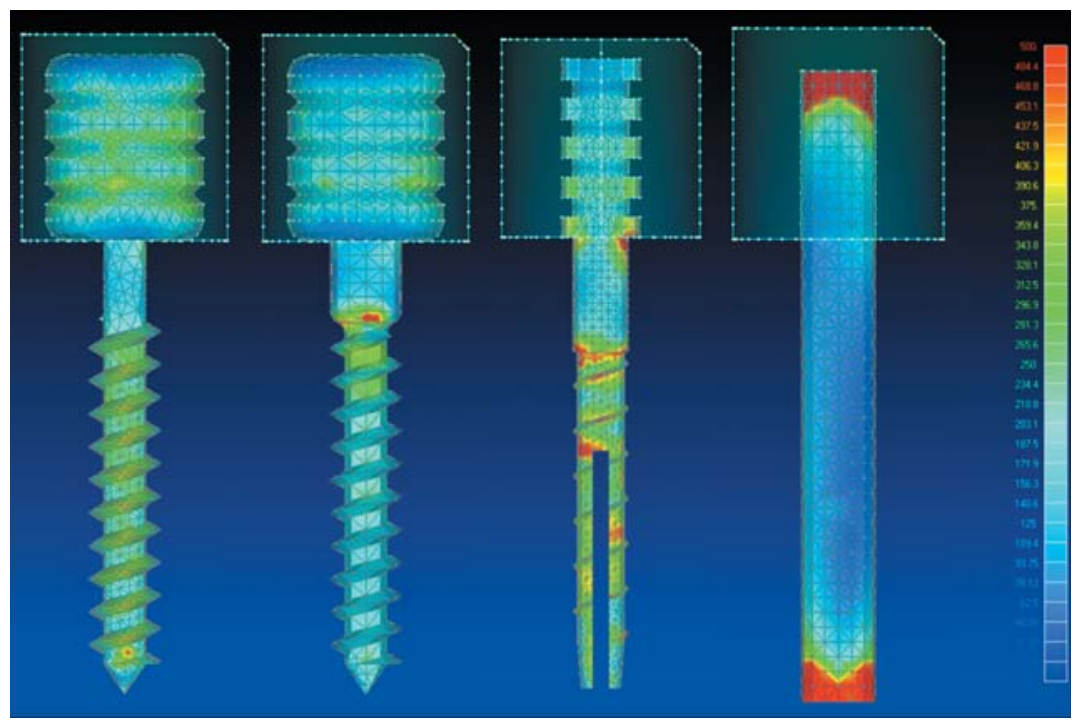

Figure 7- Color map of von Mises stresses in the posts (MPa) 
Table 3- Groups and respective type of fracture

\begin{tabular}{cccc}
\hline & Adhesive fracture of core & Cohesive fracture of core & Root fracture \\
\hline Group 1 Experimental post & 9 & 0 & 1 \\
Group 2 Modified post & 0 & 6 & 4 \\
Group 3 Flexi Post & 0 & 3 & 7 \\
Group 4 Para Post & 0 & 4 & 6 \\
\hline
\end{tabular}

Table 4- Multiple comparisons for proportions - fracture types

\begin{tabular}{cccc}
\hline Compare & Diff & q & Conclusion \\
\hline Group 3 vs 1 & 34.32 & 3.88 & Reject Ho \\
Group 3 vs 2 & 15.97 & 1.8 & Fail to Reject Ho \\
Group 3 vs 4 & 5.45 & 0.61 & Fail to Reject Ho \\
Group 4 vs 1 & 28.86 & 3.26 & Fail to Reject Ho \\
Group 4 vs 2 & 10.52 & 1.19 & Fail to Reject Ho \\
Group 2 vs 1 & 18.34 & 2.07 & Fail to Reject Ho \\
\hline
\end{tabular}

Ho: There is not a significant difference between proportions

$\mathrm{H} 1$ : There is a significant difference between proportions

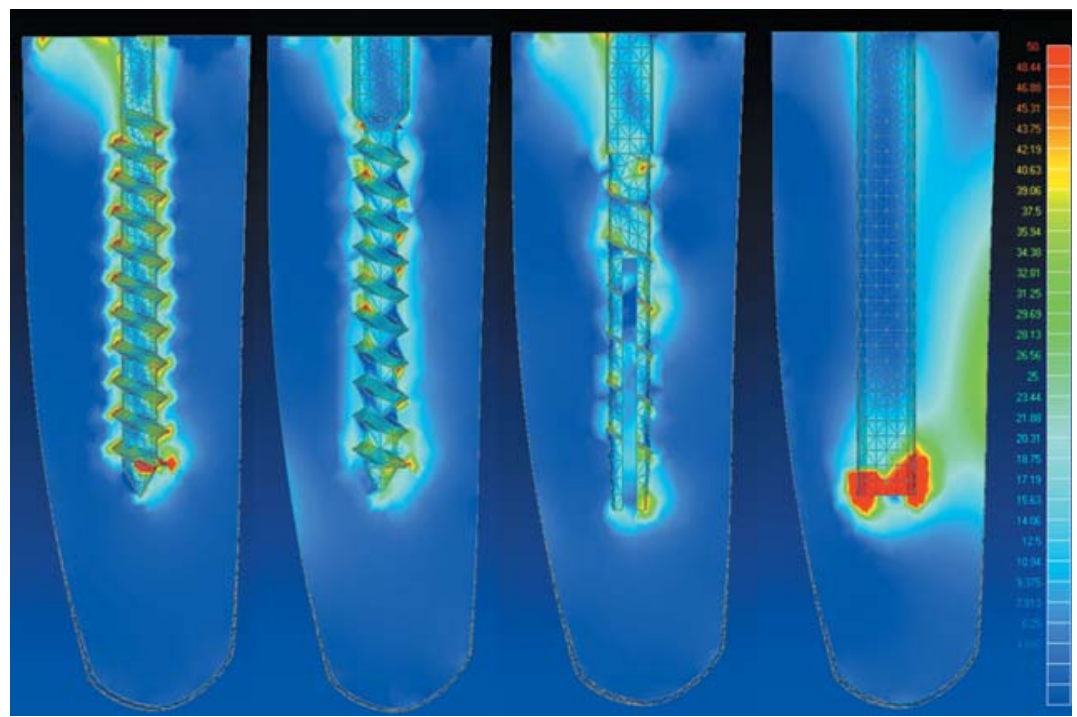

Figure 8- Color map of maximum principal stress in root dentin (MPa)

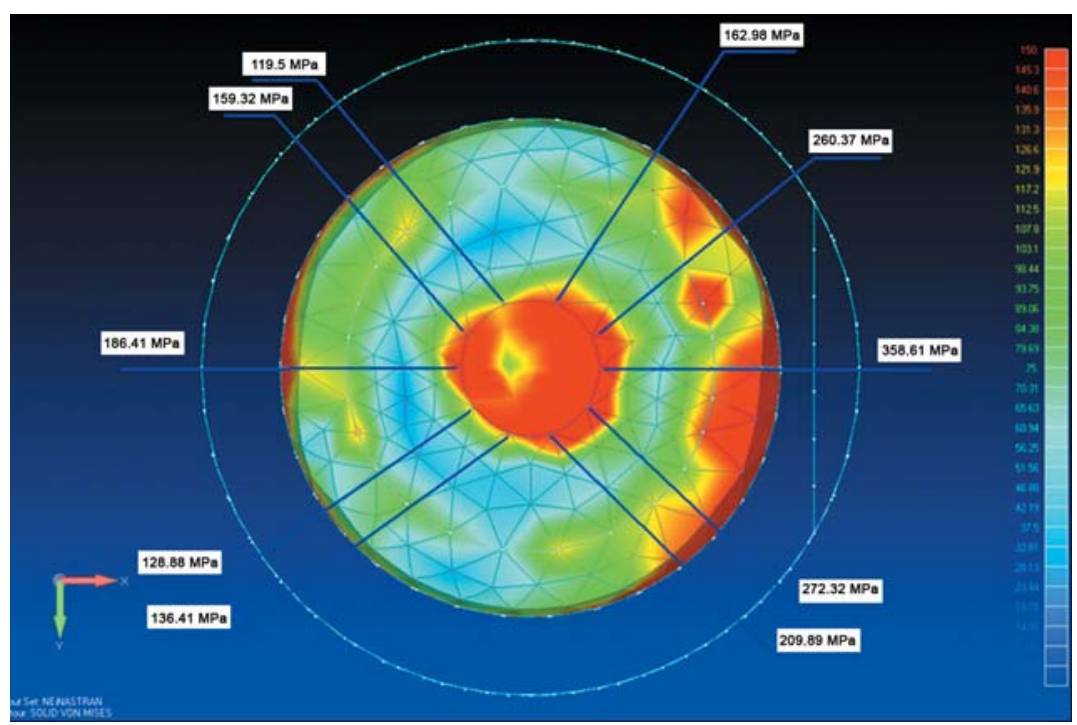

Figure 9- Color map of von Mises stresses in the neck region of the post developed in this study 


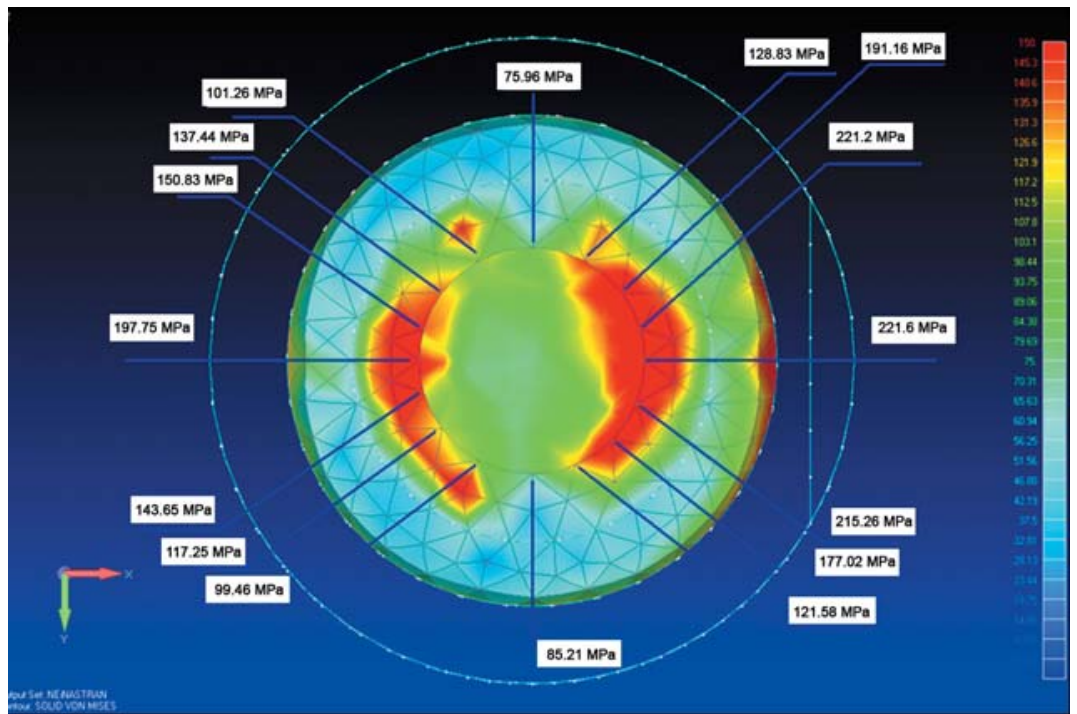

Figure 10- Color map of von Mises stresses in the neck region of the modified post developed in this study

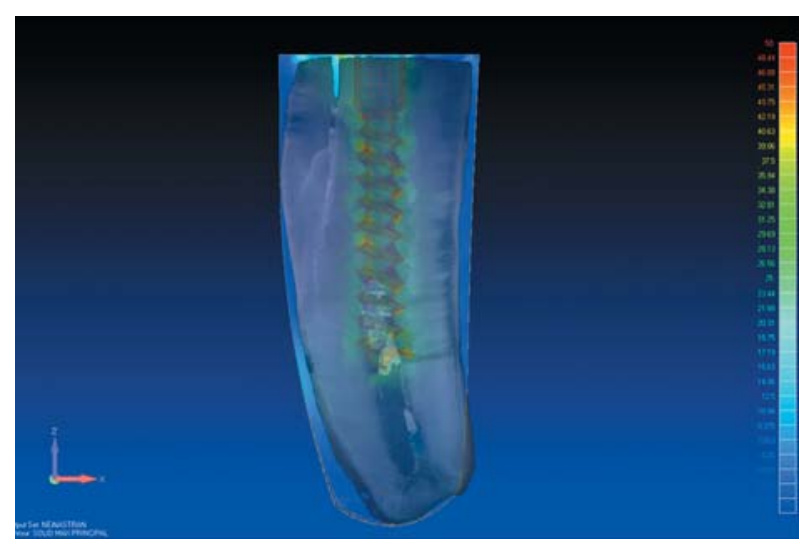

Figure 11- Overlapping image of the fracture image and the color map image of maximum principal stress obtained for group 2

similar in group 2 and group 3. A higher stress concentration was in the cervical region of dentin. In group 4, stress analysis showed a higher stress concentration in the apical region of the radicular post extending to the outer surface of the root.

Figures 9 and 10 show the stress concentration in the neck region of the post in groups 1 and 2 , respectively. The greater diameter of the neck region of the modified post in group 2 increased the frequency of root fractures. Stress analysis around the neck showed much lower values when compared with group 1 and that few regions exceeded the tensile strength of titanium.

Figure 11 shows the image of stereomicroscope photomicrograph over the finite element analysis image. The stereomicroscope photomicrograph shows the trajectory of the fracture. It can be seen that the fracture probably started in the cervical/ buccal region due to stresses generated by the load distribution of the core and followed the long axis of the tooth, accompanying the stress lines of the dentin caused by the prefabricated core.

\section{DISCUSSION}

The mean fracture resistance results observed in the present study (Table 2) are higher than the mean bite force values reported by Lyons ${ }^{15}$ (1990) for canine teeth of approximately $22 \mathrm{kgf}$. In contrast, patients with bruxism presented a bite force of almost $26 \mathrm{kgf}$ and the maximum bite force in the canine region ranged from 32 to $35 \mathrm{kgf}$.

In a study using the finite element method, Joshi, et al. ${ }^{13}$ (2001) observed that among all factors that interfere with the stress distribution pattern, post diameter and geometry contribute less to an increase or decrease of stresses in the tooth. In the present study, geometry was found to modify the stress distribution pattern (Figure 7), as demonstrated by Lewgoy, et al. ${ }^{14}$ (2003).

Posts do not reinforce debilitated teeth ${ }^{9}$, a fact that might be explained mechanically ${ }^{1,17}$. Cementation of a post during root treatment alters the load distribution pattern along its axis. The crack starts in the region of highest stress concentration (compressive or tensile stress). When the fracture line reaches the region of the intracanal post, the latter dissipates part of the stress through its body, deviating the crack in the longitudinal direction of the root $^{21}$. In addition Cailleteau, et al. ${ }^{2}$ (1992) demonstrated variations in stress concentration around a prefabricated post and suggested the occurrence of root fractures as observed in the present study (Figure 8). In agreement with these authors, we also observed a higher stress concentration around the prefabricated post. This stress concentration around posts may give origin to a crack or may help propagating an existing crack along the tooth axis, consequently causing a non-reparable fracture as observed in several of 
the fractured specimens studied here (Figure 11).

In group 1 , there was a predominance of adhesive fractures of the core of the composite resin. Tooth fracture was observed in only one case, probably because of the more tapered neck geometry of the post. The composite resin and root dentin withstood well the applied load. What occurred was bending of the post neck and consequent adhesive failure of the composite resin, displacing the post-composite resin complex but not causing root fracture. This fact might be explained by the results of the stress analysis around the post neck (Figures 9 and 10). These values exceeded the tensile strength of titanium which is about 140 $\mathrm{MPa}^{16}$, causing the neck region of the post to bend because the occlusal forces exceeded the elastic limit of the post and the core-dentin interface received the entire load.

The greater diameter of the neck region of the modified post in group 2 increased the frequency of root fractures. Root fracture was observed in 4 of the 10 test specimens. Stress analysis around the neck showed much lower values when compared with group 1 and that few regions exceeded the tensile strength of titanium. Thus, this post better withstood loads but caused a higher stress concentration in the root dentin, which probably resulted in root fractures.

The highest incidence of root fractures was observed in group 3, with 7 of the 10 specimens presenting this type of fracture. It is likely that the dentin did not withstand the stress generated by the post, causing root fracture which probably started in the cervical region where a higher stress concentration was observed.

Five root fractures were observed in group 4. Stress analysis showed a higher stress concentration in the apical region of the intraradicular post extending to the outer surface of the root. In this case, the fracture or crack had probably started in this region.

The fracture resistance results observed in the present study were similar to those reported by Mitsui, et al. ${ }^{18}$ (2004) for titanium posts and higher than those reported for the other posts studied. They observed the following fracture resistance: $36.35 \mathrm{kgf}$ for cast metal posts, $47.40 \mathrm{kgf}$ for titanium posts, $37.70 \mathrm{kgf}$ for carbon-fiber posts, $30.73 \mathrm{kgf}$ for glass-fiber posts, and $33.46 \mathrm{kgf}$ for zirconium posts.

The stress distribution pattern in root dentin was similar in groups 2 and 3. A higher stress concentration in the cervical region of dentin might have resulted in the higher incidence of root fractures in the fracture resistance test for group 3 compared with group 2 .

Specific sites of stress concentration were observed in group 3 (Figure 8). The colors changed rapidly from blue to green and yellow and a welldefined red spot was observed in the cervicalbuccal region of the post and in the apical-lingual region. These two areas of stress concentrations correspond to compression forces. In addition, the stress distribution pattern was asymmetric, with higher stress concentrations in the cervical region, as reported elsewhere ${ }^{23}$. Peak stress points were practically distributed along the whole extension of the thread in groups 1 and 2, with higher values at the lower end (Figure 7).

In group 1 (experimental post) the highest von Mises stresses were concentrated in the cervical region. It is therefore likely that the post fails before the dentin reaches the critical values shown in Figure 10. This finding indicates that finite element analysis does not comprise the phenomenon of metal plasticization or its failure.

Group 4 presented a large area of stress concentration in dentin in the apical region of the post (Figure 8 ). This area extended obliquely up to the lingual surface of the root dentin. This stress concentration is critical since this region corresponds to a transition zone between compressive stress in the apical-lingual area to tensile stress in the cervical-lingual area.

With respect to stress distribution in the intraradicular post, stress was homogenously distributed along the body of the post in group 1 , whereas high stress concentrations in certain regions were observed in the other groups (Figure 7). These stress concentrations in the body of the post induce the same stress concentration in root dentin. This was clearly observed in group 4, in which stress concentrations in the intraradicular post were centered in the region close to the site of load application and in the apical region. A large concentration in the apical region was also observed when analyzing the images of stress distribution in root dentin. Additional studies such as photoelastic analysis, micro-deformations analysis with strain gages and aging of the specimens are important for a general understanding of the subject.

\section{CONCLUSIONS}

The following conclusions can be drawn: 1 . Studies of the posts geometries can improve the stress distribution and clinical results; 2 . The experimental post (original and modified versions) presented similar fracture resistance as that of the commercial post systems tested in this study; 3 . Fewer root fractures were observed for the experimental post (original); 4. Better stress distribution in finite element analysis was observed for the experimental post (original and modified versions). 


\section{REFERENCES}

1- Anusavice KJ. Philip's Science of Dental Materials. $11^{\text {th }}$ ed Philadelphia: Saunders; 2003. 608 p.

2- Cailleteau JG, Rieger MR, Akin JE. A comparison of intracanal stresses in post-restored tooth utilizing the finite element method. J Endod. 1992;18(11):540-4.

3- Christensen GJ. Posts and cores: state of the art. J Am Dent Assoc. 1998;129(1):96-7.

4- Clavijo VG, Reis JM, Kabbach W, Silva AL, Oliveira Junior OB, Andrade MF. Fracture strength of flared bovine roots restored with different intraradicular posts. J Appl Oral Sci. 2009;17(6):574-8. 5- Cohen BI, Pagnillo M, Musikant BL, Deutsch AS. Comparison of the retentive and photoelastic properties of two prefabricated endodontic post systems. J Oral Rehabil. 1999;26(6):488-94.

6- Completo A, Fonseca F, Simões JA. Modelo numérico e experimental da tíbia intacta e com componente tibial da prótese do joelho. Mecânica Experimental. 2006;12:77-98.

7- Garbin CA, Spazzin AO, Meira-Júnior AD, Loretto SC, Lyra AM, Braz R. Biomechanical behaviour of a fractured maxillary incisor restored with direct composite resin only or with different post systems. Int Endod J. 2010;43(12):1098-107.

8- Geng JP, Tan KBC, Liu GR. Application of finite element analysis in implant dentistry: a review of the literature. J Prosthet Dent. 2001;85(6):585-98.

9- Guzy GE, Nicholls JI. In vitro comparison of intact endodontically treated teeth with and without endo-post reinforcement. J Prosthet Dent. 1979;42(1):39-44.

10- Henry PJ. Photoelastic analysis post core restorations. Aust Dent J. 1977;22(3):157-9.

11- Ho MH, Lee SY, Chen HH, Lee MC. Three-dimensional finite element analysis of the effects of posts on stress distribution in dentin. J Prosthet Dent. 1994;72(4):367-72.

12- Jamani KD, Harrington E, Wilson HJ. Rigidity of elastomeric impression materials. J Oral Rehabil. 1989;16(3):241-8.

13- Joshi S, Mukherjee A, Kheur M, Mehta A. Mechanical performance of endodontically treated teeth. Finite Elem Anal Des. $2001 ; 37: 587-601$.
14- Lewgoy HR, Youssef MN, Matson MR, Bocangel JAJS, Netto CA, Amore R. Finite elements study of the Flexi Post and Flexi Flange post systems in a maxillary central incisor. Pesqui Odontol Bras. 2003; 17(2):132-6.

15- Lyons MF, Baxendale RH. A preliminary electromyographic study of bite force and jaw-closing muscle fatigue in human subjects with advanced tooth wear. J Oral Rehabil. 1990;17(4):311-8.

16- MatWeb - Material Property Data [homepage on the internet]. SI:Matweb;2005 [cited 2008 ago 4]. Available from: <http:// www.matweb.com.br>.

17- McDonald AV, King PA, Setchell DJ. An in vitro study to compare impact fracture resistance of intact root-treated teeth. Int Endod J. 1990;23:304-12.

18- Mitsui FH, Marchi GM, Pimenta LA, Ferraresi PM. In vitro study of bovine roots using different intraradicular post systems. Quintessence Int. 2004;35(8):612-6.

19- O'Brien W. Dental materials and their selection. $2^{\text {nd }}$ ed. Ann Arbor: Quintessence Publishing Co.; 1997. p. 331-406.

20- Sano H, Ciucchi B, Matthews WG, Pashley DH. Tensile properties of mineralized and demineralized human and bovine dentin. J Dent Res. 1994;73(6):1205-11.

21- Schilke R, Bauss O, Lisson JA, Schuckar M, Geurtsen W. Bovine dentin as a substitute for human dentin in shear bond strength measurements. Am J Dent. 1999;12(2):92-6.

22- Smith CT, Schuman NJ, Wasson W. Biomechanical criteria for evaluating prefabricated post-and-core systems: a guide for the restorative dentist. Quintessence Int. 1998;29(5):305-12.

23- Standlee JP, Caputo AA. The retentive and stress distributing properties of split threaded endodontic dowels. J Prosthet Dent. $1992 ; 68(3): 436-42$.

24- Terry DA, Tiolo PT Jr, Swift EJ Jr. Fabrication of direct fiberreinforced posts: a structural design concept. J Esthet Restor Dent. $2001 ; 13(4)$ :228-40. 